\title{
And yet they thrive!-Regaining the relevance of a transparency system
}

\section{Pontus Hedlin}

Stockholm Business School, Stockholm University, Stockholm, Sweden

\section{Correspondence}

Pontus Hedlin

Email: pontus.hedlin@sbs.su.se

\begin{abstract}
Over the past decade, a host of donor organizations implemented transparency systems to make international development aid more transparent to the public. These initiatives have met with little public interest, but their proliferation and development show no sign of diminishing. This article shows how internal importance to the political system, fueled by formal rankings and the exhibition of transparency systems as a flagship initiative, can replace relevance to the public as a driving force for sustainable development. The article concludes by discussing the possibility of a future development where transparency systems finally do connect with user groups, such as citizens of both donor and recipient countries, and gain a relevance even beyond original intentions.
\end{abstract}

\section{K E Y W O R D S}

aid transparency, transparency systems, user relevance

\section{1 | INTRODUCTION}

Over the past ten years, the international transparency agenda has started to pick up momentum both on a more general level, but also specifically for international development aid (McGee, 2013). On a more general level, things started to happen with the new Obama administration and its Open Government agenda, where government administration was being opened up and made more transparent with the aid of information technology (Linders, 2013). New technology was seen as enabling communication between government, agencies and the public in new and innovative ways and it was seen as particularly important to realize some of the potential offered by recent developments in 
information technology, not only the Internet and web-based technology, but also smartphones and apps.

The ideas of the Open Government agenda started to filter into the political leadership of Swedish international development aid via open data enthusiasts. This also coincided with domestic ideas about pro-active government openness. As a result, the Swedish Government issued a political reform - the Transparency Guarantee - effective from 2010, which promised full transparency in all Swedish international development aid. At the time, the field was fraught with tensions between the political system and the development aid community and for that reason the Transparency Guarantee was seen by many in the aid industry as a means of management control, i.e. a way to put pressure on the development aid administration to be more effective. Nevertheless, the political commitment to development aid was not challenged by the reform. Also, the Transparency Guarantee was in line with international developments and commitments. According to the political leadership at the time, the reform was questioned internally by officials at the Ministry for Foreign Affairs more than it ever was politically or by the public.

All this happened at a time when Swedish international development aid had been the subject of considerable reform by the government. Government spending had been raised to $1 \%$ of GNI, which was rather uncontroversial in parliament as well as among the majority of the public. The focus of considerable debate was how resources should be spent, how many and which countries should receive aid, the role of different agencies and organizations in the distribution of aid. Much of this was subject of fierce parliamentary and public debate, but the general spending target and the Transparency Guarantee were not.

The initiative to enhance transparency soon led to the development of a web application for the distribution of public documents and information about Swedish international development aid. The application being developed was named Openaid and was designed to be the hub of a national transparency system for Swedish international development aid. Developing a transparency system for development aid at this time was not unique to Sweden. On the contrary, the years 2010-2012 saw a concerted increase of transparency systems.

As a result of international development and commitments, many donor countries and other international aid organizations launched transparency systems during this period. Since then, the field of transparency in international development aid has been buzzing with activity. The general idea has been that transparency systems would stimulate public interest in international development aid and that it would also start dialogues and processes that would enhance transparency, accountability and effectiveness (Linders, 2013).

However, a couple of years after this development began, research on transparency systems showed a mixed bag of results and we still know very little of their effectiveness and impact (Gaventa \& McGee, 2013; Mejía Acosta, 2013). Some research has indicated positive impact, whereas other reports show disappointing results and also that in many cases it is still too early to determine what effect they have had on long-term goals (Carter, 2014). Thus far the effectiveness and impact of transparency systems is largely assumed (Joshi, 2013).

One reason for the rapid spread of transparency initiatives is due to the fact that transparency as a concept and panacea is very much in vogue (Hale, 2008). Avila, Feigenblatt, Heacock, and Heller (2011), Carter (2014) and Kuriyan, Bailur, Gigler and Park (2012) emphasize that information technology is rapidly transforming the field of transparency. Tisné (2010) and many others see this as something that is just beginning and that the possibility and promise of catalytic change through information technology is still unrealized. This may explain why developments in the field of transparency systems for international development aid show no sign of losing momentum. 
The hope nurtured by Tisné (2010), Linders (2013) and others is that information technology, based on open data and open platforms, will transform international development aid, just like open ecosystems such as personal computers, the World Wide Web and smartphones have sparked innovation and reshaped other sectors of society (O'Reilly, 2010).

Despite the increased use of information technology, a major disappointment has been the inability to arouse the interest of the public. Researchers have found it to be conspicuous by its absence (McGee, 2013). This is curious, since transparency systems are for the public. Or, aren't they? One might expect that public demand would either be a driving-force for the spread of transparency systems or that they are at least being developed by benign benefactors on behalf of the public. And if so, one might expect transparency systems which fail to find an audience doomed to wither away and quietly die. This does not seem to be the case.

Previous research points to several anomalies or, at least, what seem to be blind spots in our understanding of transparency systems for international development aid. They might not work as intended. They seem to have few users, which indicates a lack of public interest. And yet, they thrive! This raises the question whether there are other forces at play, besides public demand for transparency systems, which are key driving-forces in their development and proliferation. If so, what are the implications?

\subsection{The research question}

The enigma at the heart of this investigation is what forces are driving the advent and development of transparency systems for international development aid. Previous research indicates that a public hunger for information could not explain the emergence, nor the dynamics of further development, of transparency systems.

The strategy to solve the enigma is to describe and analyze the emergence of a transparency system for Swedish international development aid - Openaid - and to investigate what forces and actors are shaping it.

The research question is: What are the driving forces behind the emergence and further development of Openaid?

The purpose of the investigation is to contribute to the literature of the development and dynamics of transparency systems in general and for transparency systems for international development aid in particular. The article will draw conclusions based on the development so far, but also discuss implications for the future.

\section{$2 \mid$ METHOD}

The research strategy is explorative, since the phenomena under investigation are relatively new and still under development. Furthermore, previous research in the field is still limited and points in different directions.

The basic method has been to analyze an empirical case in terms of its background, realization and present functioning. The empirical case is the story of how the Swedish Transparency Guarantee came to be implemented in the form of an internet-based transparency system - Openaid.

Its background is important for understanding why it came about. Juxtaposing how Openaid currently functions with theoretical ideals for how transparency systems should function provides a frame of interpretation. Finally, the story of how the Transparency Guarantee came to be realized provides us with some of the explanations of why discrepancies between realization and theoretical ideals arose. 
The material used in the research project consists of several sources; literature on transparency with a specific focus on transparency systems in general and on transparency systems in international development aid in particular; archive documents concerning Openaid; traffic reports from Google Analytics mapping the use of Openaid and interviews with different actors in the field of transparency in Swedish international development aid.

Much of the literature referred to is quite recent, since it deals with the empirical focus of the project, transparency systems in development aid, which in itself is a rather new phenomenon. This literature has been supplemented with more general literature on transparency and transparency systems. These articles help to disentangle central concepts, but they also contribute by providing a framework for interpreting empirical findings.

Most of the empirical narrative is drawn from archive documents from the Ministry for Foreign Affairs and Sida (Swedish International Development Cooperation Agency). These documents are working documents, protocols and plans. relating to the Transparency Guarantee and Openaid. This has been supplemented with traffic reports from Google Analytics showing the use of Openaid. The traffic reports show not only the number of hits on a website, but also the behaviour of visitors.

The final component of empirical material has been interviews with 32 people, each interview averaging 47 minutes. The interviews were explorative and open, based on a check-list of topics to be covered. Interviewees were employees in different capacities at the Ministry for Foreign Affairs and Sida, Openaid project members, journalists covering development aid, researchers, party spokespersons in parliament for development aid, NGO representatives and others connected with the empirical narrative. The interviews deal with the background and development of Openaid as well as current use and transparency issues.

Taken together, the documents and interviews contribute to a rich and multifaceted description of the case - the background, development and use of Openaid - since each contributes with its own different piece of the story and its own specific outlook on events.

The interpretation of the empirical material has been undertaken from two perspectives. The first is that the interpretation and organization of the empirical material has been organized around themes and concepts from the theoretical literature. Secondly, Openaid as a transparency system has been juxtaposed with the theoretical framework emerging from the literature on transparency and transparency systems, discussed below. The reading of previous research and theory on transparency systems has resulted in an ideal image with which Openaid has been compared to highlight interesting similarities as well as differences. Here, previous research and literature has also helped to explain differences and anomalies as well as findings in line with expectations.

\section{TRANSPARENCY AND TRANSPARENCY SYSTEMS}

Calls for more transparency in numerous sectors reflect a universal trend (Florini, 2000). In recent years, we have witnessed many efforts to create transparency and accountability in diverse areas such as the environment, health, economics and human rights. Many of these initiatives are based on private or communitarian efforts, but Bertot, Jaeger and Grimes (2010) and Fox (2007) show that there is also a trend towards transparency that is promoted by governments all over the world. Some initiatives concern the openness of government, whereas others aim at creating organizational transparency regarding environmental sustainability or human rights (Belal, Cooper, \& Roberts, 2013; Brown, Jong, \& Lessidrenska, 2009; Gallhofer, Haslam, \& van der Walt, 2011).

Different transparency initiatives are often launched in the form of comprehensive systems. We find this idea to some extent in Joshi, when defining transparency initiatives as "any attempts by states 
or citizens to place information or processes that were previously opaque in the public domain" (Joshi, 2013). This is perhaps not very ambitious, since it covers both meagre and unsystematic initiatives. Fung, Weil, Graham and Fagotto (2004, p. 1) are a bit more demanding when defining transparency systems as "government mandates that require corporations or other organizations to disclose information about their actions in a comparable manner and at regular intervals". Transparency systems have traditionally worked in a cyclical fashion, where information is disclosed, acted upon by recipients, which in turn leads to a corresponding action or dialogue from the discloser. In the ideal model for transparency systems, described by Fung et al. (2004) and Hale (2008), the dynamics create an action cycle based on a dialogue between information user and discloser. The underlying metaphor is a friendly and trusting conversation. Establishing trust is essential since a pure transparency system has no formal mechanisms to enforce quality control. Nor does it have the mechanisms to sanction inappropriate behaviour or substandard performance revealed by the information given. A pure transparency system can foster accountability, but it has no mechanism to enforce it.

For a transparency system to function properly, and an action cycle to be established, it is either necessary for information users to have a strong position in relation to the discloser, or for the discloser to have a genuine commitment for moral reasons. If not, disclosure will most likely be selective. But even when there is a genuine commitment from disclosers, Hess (2007), among others, shows how there might be a need for third parties to interpret and repackage complex information that is open to misinterpretation. Indeed, in several sectors we find that the third parties form their own industry of analysts, journalists and activists. When we are dealing with complex information, third party infomediaries are needed to collect, interpret, repackage and disseminate information (Weil, Fung, Graham, \& Fagotto, 2006).

In many transparency systems, there are strict standards for reporting and also formal quality controls to make sure that reports are comprehensive and correct. Auditors or other formal functionaries inspect disclosed material to assure its quality. In this case we have established procedures for both disclosure and quality control and these procedures presuppose that reports and the material upon which they are based are well-defined and that measurement principles are agreed upon. The model is based on the assumption that certain aspects of an organization's activities are more relevant than others for information users. The cyclical transparency system handles specific, predefined reports, which is different from general openness policies. A disclosure model is cyclical in nature, whereas an openness policy is reactive, rather than proactive. It produces specific information that is asked for on request. As a consequence, the information handed out can often be very different in nature.

The distinction between general openness and specific disclosure on the one hand, and reactivity and proactivity on the other, has been erased, or at least blurred, in recent years with the advent of open book government. Linders (2012) and Janssen, Charalabidis and Zuiderwijk (2012) describe how citizens can follow government action and performance directly on the Internet, thereby potentially leading to benefits such as increased transparency, democratic accountability, citizens' participation in public processes, stimulation of competitiveness, innovation and knowledge development as well as supporting easy access to data and reuse of data.

In the open book government model, all data that is available upon request should also be available online so that citizens can search and request public records by using simple search criteria, which by proponents of the model is expected to create not only transparency but also dialogues and dynamics that enhance government processes. Data is published as a continuous stream as it is being generated. This is different from the traditional disclosure model which is also proactive in nature, but discloses predefined and selected information at regular intervals and in a repetitive format. It is also different from the traditional openness model, where information that is subject to openness is handed out on request. The findings of Kalampokis, Tambouris and Tarabanis (2011) indicate that the main trend 
in transparency systems is that a plethora of government data is made available in machine-readable format, so that it can be reused, combined with other machine-readable data and processed by users.

Often, however, it is unclear how the available government data should lead to improved processes, and there are obvious problems with the notion that improved access to data automatically leads to feed-back processes, which in turn results in improved government processes. A first prerequisite for all succesful transparency systems is that they reach interested users with whom a dialogue can begin. This is often not the case. McGee (2013) shows how most recent transparency systems seem to be constructed on the premise of 'if you build it, they will come', with 'they' being citizens rushing towards the accessible data.

A basic problem, Carter (2014) contends, with this approach, is that there is seldom a clear understanding of who 'they' are. Just making raw data available on the Internet does not mean that enthusiastic users will gather like ants scenting syrup. They won't. Access is not only about making data available, but also about facilitating our ability to make sense of it (Mejía Acosta, 2013). Often raw data need to be modified to be intelligible and used and sometimes it requires expertise to make sense of data and what it implies. To some extent these are problems that can be overcome, or at least mitigated, by presenting and packaging data in a more user-friendly manner, but the main problem identified by Janssen et al. (2012) is often that transparency systems seem to be based on reversed engineering in the sense that they take their point of departure from what suppliers can deliver, rather than what identified user groups would be interested in.

For any organization that wishes to show that it has taken steps to be more transparent it is easy to supply prospective users with a container of raw data to collect and do with what they will. However, abundance of data is often more problematic than beneficial for users. Just making it retrievable does not mean that it will be used. Nor does it mean that, if it is used, it will be used in a sensible way. Furthermore, a proven strategy for hiding needles of unfavourable information is to hide them in a haystack of data. Visibility can conceal and items can be hidden within other items (Strathern, 2000).

An abundance of raw data may be confusing and of little value to individual end users. On the other hand, if raw data are published according to open standards and can be downloaded in bulk by third parties, they can serve as a platform for reuse and even innovation (Robinson, Yu, \& Felten, 2010). The open standards would then also permit presentation to end-users which are based on combining data from multiple transparency systems. Innovative combination and presentation of data would then have the potential to spark interest and lead to user engagement.

For transparency systems to be of interest to users, there must be dialogue. If users are absent, we have no dialogue, and for many transparency systems this seems to be the case. Many initiatives have resulted in transparency systems where the only noticeable action taking place seems to be when the disclosing organization is adding new data. Nevertheless, new initiatives for transparency have abounded in recent years and the field shows no sign of decreased construction activity (Gaventa \& McGee, 2013). This is perhaps both a result of developments in information technology and faith in the transforming potential of transparency as a concept.

International development aid has, more than most other sectors, witnessed a surge in transparency initiatives over the past five to ten years. Developments in transparency systems for development aid have so far focused on making the spending of donor funds transparent (Linders, 2013). Not only has donor spending been in focus, but McGee (2013) also shows that it has also been so from a specific perspective, which is a taxpayer's, rather than an aid recipient's. It has been pointed out by Tisné (2010), that for transparency systems to be instrumental in transformative change, they also need to reach the aid recipient community. This, however, seems like quite a distant goal, since most transparency systems still do not even reach a household audience. Most transparency systems have so far not succeeded in interesting the public in their home countries, or, as McGee puts it: "Where are the 
accountability-seeking citizens on whom the aid transparency edifice rests? They seem conspicuous by their absence in the conception and execution of most transparency and accountability initiatives" (McGee, 2013, p. 122).

Absence of public interest is a serious problem that needs to be overcome for several reasons. User involvement is not only necessary to achieve policy goals, but the user dialogue is also a prerequisite for sustainable long-term development and adaptability to changing circumstances (Fung, Graham, \& Weil, 2002). For a while, transparency systems for international development aid could probably continue to evolve "inside a bubble", generated by political commitments, but not in the long run. In the long run, transparency systems must perhaps also be perceived to be of interest to the public in order for the political system to find it worthwhile to continue investing in them.

Initiatives sometimes fail to contribute to transparency. Some do so because they were never meant to provide transparency and others because they just failed to connect, to create an ongoing dialogue. Perhaps they were poorly designed. Others might have been successful to start with, but gradually lost their relevance. Why? Hess (2007) argues that, once implemented, a transparency system must evolve over time to increase, or even keep, its relevance. This is in line with the findings of Fung et al. (2004), demonstrating that continuous improvement in several dimensions, such as use, accuracy and scope, is necessary for sustainability.

Part of the dialogue that a relevant transparency system constitutes needs to concern not only a discussion of the content of information and if and how this should be acted upon, but also how the dialogue itself could be improved. In some cases, feedback processes for improvement is also part of the system design (Weil et al., 2006). This doesn't mean that there needs to be a perfect fit between policy objectives, user needs, system design and so on, merely that change is often necessary for continued use and relevance. Also, by the same token, use and relevance is necessary to generate feedback for development. Feedback for change is part of a dialogue. No dialogue, no feedback.

Fung et al. (2004) describe the model for disclosure, dialogue and feedback in terms of a "transparency action cycle". The model below is a slightly modified version, where a few additional elements outside the circle of action have been added:

The idea is the following; (1) a transparency system, (2) compels government agencies and other organizations to disclose information about their activities to the public. (3) If this information is found to be useful to some citizens (4) they act upon the information (5) in ways that are discernible to and noted by the discloser (6) and the discloser responds by engaging in dialogue or by otherwise taking action. The action may result in a change of conduct, but it may also result in a modification of the transparency system. The latter part is what makes the transparency system sustainable - the ability to change in response to user action.

A significant obstacle is that disclosed information is hard for users to digest. This is a problem since for the information to be of use it must be comprehensible (Weil et al., 2006). It is difficult to act upon data that is too comprehensive or too complex and for many transparency systems it is both. This is why third party infomediaries are important (Hess, 2007). Without them, the action cycle breaks down.

Third parties act as infomediaries and can intervene to collect, interpret, repackage and disseminate information in a digestible form to users. This can be in many different roles; as journalists, as politicians moulding public opinion as activists. These roles are essential, since users are likely to underconsume information if it hasn't been processed and presented in intelligible form by infomediaries.

Third party infomediaries could ultimately provide their own transparency systems, based on combinations of data from multiple sources, when original data are published for free in standardized and machine-readable format. In fact, this is when innovation is most likely to occur (Robinson et al., 2010). 
There is also another important role for third parties that is different from that of infomediary that of watchdog. As pointed out by Fung et al. (2002), the very design of a transparency system can include watchdog intervention for audit or periodic assessment, but the role of watchdog can also be self-proclaimed by organizations. Not only can the watchdog have a formal appointment or be entirely self-proclaimed, but it can also have a different focus. The focus can be on the content of information, which is the operative action of the discloser, but it can also be on the functioning of the transparency action cycle, i.e. the information process rather than the conduct of the discloser.

The transparency action cycle model presented above provides an object for juxtaposing empirical findings. It is an over-simplified model of a much messier and more complicated process, but nevertheless gives us a starting-point for reflecting on actors, driving forces and their relations. We shall see how it can be applied to Openaid.

\section{4 | OPENAID - EMPIRICS AND DISCUSSION}

As a result of several driving forces, the Swedish government in 2010 decided to develop a transparency system for international development aid called Openaid. Unfortunately, Openaid's requirement specifications received some major restrictions right from the start. Already in the tender it was made clear that the project and the application developed would be data-driven. Data would be presented and visualized on different levels and by country, sector and organization, but it was also made very clear in the tender from May 12, 2010 that:

"... the editorial content of the web application will be minimal and mainly consist of explanatory texts to explain the development aid chain and the content of the data-base."

So, from the start, the project to develop Openaid was very much data-driven and did not take different user group scenarios as a point of departure for development. This meant that nobody in the IT project assessed what could be important or interesting for intended user groups like journalists, activists, schoolclasses and their teachers and researchers. In fact, nobody really knew which the important user groups would be.

On April 4, 2011, Openaid was launched to the public. The launch included a pre-presentation before a panel of experts on development aid, open data and transparency. The expert panel was perhaps not overly impressed, but could see the potential in making the data public, and one of its members even remarked: "A splendid first step!" Things were looking rather promising and everything was in place to go live.

Openaid was ready to start delivering information to an information-hungry public. There were feedback mechanisms in place to capture and document user feedback and there was an organization in place that was ready to engage in a dialogue based on the feedback.

How does all this, so far, fit into the transparency action cycle discussed previously? How was the intended Openaid action circle supposed to work? The idea would be something along the following lines:

(1) The transparency system (2) compels all agencies and organizations funded by Swedish official development aid to report documents, descriptions, disbursements and results on an activity level. (3) The public finds the information very interesting and (4) starts to ask questions about priorities made, the spending of resources, suspicions of corruption and misspending as well as results achieved and also proposes ideas on how transparency and the transparency system could be improved. (5) Questions concerning different activities are furthered to the appropriate granting 


\section{Transparency Action Circle}

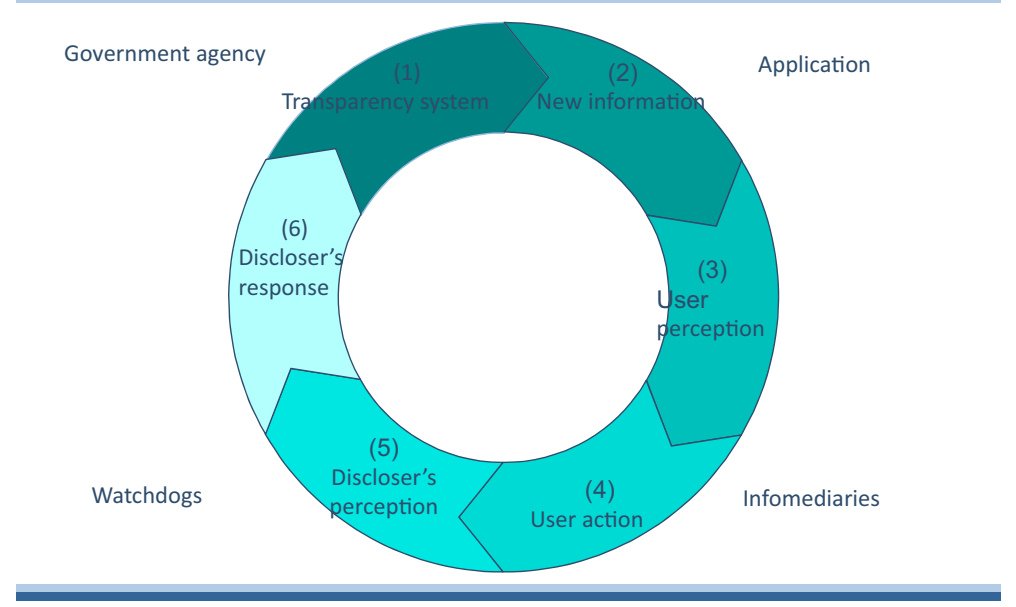

F IG URE 1 Transparency action circle

agency which engages in a dialogue with the enquirer, and questions regarding the functioning of the action circle itself are picked up, after which (6) action in the form of system change, engagement in dialogue with user, investigation of suspected corruption or misspending is initiated depending on circumstances. The dynamics between user, discloser and administrator of the transparency system will lead to improvements in the Openaid transparency system itself. Thus, the intended Openaid action circle corresponds with the Transparency action circle (Figure 1) described by Fung et al. (2004).

To aid in the process there would be interested press, activists from NGOs and political organizations to collect, interpret, refine, repackage and disseminate the information in the form of articles, actions and discussions. There would be watchdog institutions to oversee both the process and the activities. An important role would be played by third-party organizations who would scrutinize information content. Furthermore, the scrutiny of spending and results would, when necessary, lead to audits and investigations of aid activities.

In this model, it is the interplay and dialogue between the administrator, discloser and the citizen as user that is the driving force that creates a dynamic for the whole system.

\section{1 $\quad$ The launch and use of Openaid}

The launch of Openaid was given some media coverage. It was mentioned in the government newsletter, the business press and also in Sweden's largest daily newspaper. Naturally, everybody in the development aid sector was also informed. The word was out. The question was; what would happen when the doors were opened? What would the reception by the general public be like? Would journalists take out their digital shovels and start digging? Would school classes start projects that would lead to an onslaught?

Nobody really knew what the reception from different groups would be; perhaps interest, anger, applause? Certainly, there would be reactions to deal with. One of the many who was full of anticipation was the Minister of international development aid herself: 
"There was almost a crisis organization at the public launch. We were on our toes, because now all the questions would come rushing in. How should we answer? Who has the answers? It won't explode, but things will start happening! Well, it didn't. It was like a slow puncture! It became an anti-climax!”

To the surprise of those involved, practically nobody showed any interest. The public didn't show up. And so it started, not with a bang, but with a whimper. Perhaps not even that.

Openaid did not attract the initial public interest its originators had hoped for. Furthermore, not only was its premiere a quiet occasion, its continued existence has so far been characterized by the indifference and absence of the ordinary citizen. This is evident both from traffic reports, showing the number of visitors, and the use of feedback mechanisms in Openaid. This should perhaps come as no surprise, since it is in line with previous research (McGee, 2013).

Like many web applications, Openaid has from the start contained mechanisms for feedback and discussions. The idea was to establish fora for a dynamic user dialogue, but just as the expected feedback at the start of Openaid never happened, so the ongoing feedback came to practically nothing. The person in charge of the user dialogue stated:

"The past six month there has been very little. We get one comment a month, tops. It's not a very lively discussion."

Perhaps we shouldn't be overly surprised that few non-professionals have made it a pastime to sift through raw data and documents which are mostly on a detailed activity level. It requires a form of scrutiny that is both complicated and time-consuming.

If Openaid presents data and information that is too hard for the ordinary citizen to digest, maybe it is better suited for professional third party intermediaries that work within the field of international development aid? Third party professionals who could make use of the information, repackage it and present it to the public, include journalists and politicians specializing in the field as well as prominent NGO activists. However, little in the information they disseminate indicates that they themselves use Openaid as a source of information. When asked about this in interviews it turned out that practically none of them used Openaid as a source of information. Why? They found the information too detailed and complex. If that is the case with seasoned professionals, we can't expect the ordinary citizen to find the website of much interest.

Consequently, the level of detail and complexity explains why Openaid is not used by citizens, journalists and many professionals. Even so, traffic reports show that even though the activity is low, there are users. The traffic reports also reveal who the primary users are. The typical user of Openaid does not spend time on browsing or exploring available information. Nor does she spend time on sorting aggregated information in different ways. In fact, the typical user shows little sign of exploring the website. Instead, she goes quickly in-and-out to check facts or to retrieve documents. This "administrative use" is explained by the fact that the primary user is an aid professional, working at Sida, for whom it is a convenient way to access information and documents relating to specific projects in connection with work activities such as meetings and writing reports.

Additionally, there is a user that doesn't show up in traffic reports, no matter how thoroughly they are studied. It is a user for whom Openaid is highly important, even though this user rarely visits the website; the political system. After its launch, Openaid has received much more attention from the political system than from the public. It was presented to other branches of government as a model example of transparency and, since no other branch of Swedish government had anything like it, it also came to be showcased to foreign government representatives and to 
represent Sweden in the Open Government Partnership (OGP), a multinational co-operation to enhance government transparency, even though a report on behalf of the OGP expressed the conviction that responsibility for Sweden's participation should be transferred to a government body with broader oversight:

"Most of the consulted stakeholders agree that future OGP commitments should be broadened beyond the field of aid transparency. However, the current OGP coordinator, the MFA, cannot enforce broader policy commitments in other branches of government. Hence the OGP coordination should be placed in the hands of another entity."

That never came to pass for the simple reason that there was nothing like Openaid in other branches of government. Therefore, it became a flagship for the political system as a whole, not only for the part of the Ministry for Foreign Affairs which handles development aid, and it was flaunted internationally as well as domestically. In terms of comprehensive transparency initiatives, Sweden had nothing else to flaunt and no other branches of government have since followed the example.

To sum up the use of Openaid so far, we can see that there is little use by the general public, as was shown by previous research (McGee, 2013). However, we can also see that there are signs of life. Openaid has become a tool for internal use by Sida staff and also of importance to the political system. This explains why investments have been made in its further development.

\section{2 | Further development of Openaid}

Since its launch in 2011, development of Openaid has continued, but with slightly different foci compared to the original project. The needs of internal users were explicitly expressed to be prioritized in the project plans when application development recommenced after the launch. This was reasonable since internal users, in the form of employees of Sida, seem to be the dominant user category showing up in traffic reports. Also, catering to the needs of employees was not even among the requirements when the application was originally designed and developed.

A major shift in development focus after the launch of Openaid was the effort to become compliant with the international data standards for development aid provided by International Aid Transparency Initiative (IATI). This might seem like a technicality, but empirical evidence, as we will see, suggests that it is important for three reasons; comparability, commitments and prestige. Each of these was an important driving force for the further development of Openaid.

The first of the driving forces is comparability. For aid data from the transparency systems of different organizations to be comparable, they have to have common definitions concerning meaning, format and so on. This is provided by the IATI standards. IATI provides a technical framework for publishing data about organizations and activities. The data in the form of numbers concerning Swedish international development aid can thus be compared to and/or aggregated with that of other aid organizations and also non-financial information can easily be retrieved in a data-set, since the standard specifies where it is to be found. So, in one way or another, the IATI standards provide the common descriptions for comparing data from different organizations. Not only does IATI provide a technical standard for publishing data, but it also provides a datastore, the IATI registry, which gathers data from all organizations published to the IATI standard. The registry can be queried or downloaded for analysis or use in third party applications.

The second driving force is commitment. Sweden and many other countries and donor organizations have signed international commitments to implement IATI standards and are being held responsible for honouring those commitments in time. Not all organizations see joint declarations as 
promises that have to be fulfilled, which history clearly shows, but working documents from Sida and the Ministry for Foreign Affairs make it obvious that this commitment was taken seriously. In fact, so seriously as to merit much extra development effort when the IATI registry was launched, since the original Openaid version was developed before the IATI standard was settled upon, which meant that Openaid data exports to the IATI registry had to be reformatted into IATI standard. In a later release of Openaid its database was adjusted to IATI standard, but the commitment to publication of data in standard format was there from the very beginning.

The third driving force is prestige. Being IATI compliant is not only a matter of making data comparable and honouring international commitments. It goes far beyond that in the world of international development aid. Why? Because every year the Aid Transparency Index is published by Publish What You Fund (PWYF), an independent organization dedicated to investigating and campaigning for development aid transparency. The Aid Transparency Index scrutinizes and publishes measures of donor organizations' transparency in their reporting and is as important for gaining prestige in the development aid sector as Guide Michelin is to high-end restaurants, since it establishes a pecking order among donor organizations. It is also very influential for another reason. Its criteria are open, concrete and actionable. The result of each year's ranking can be used as a roadmap for development to improve the score in future rankings.

The Aid Transparency Index is primarily based on two factors, which are each broken down into many detailed criteria. The two factors are the level of the donor organization's commitment to transparency and the other is the degree of compliance with IATI reporting. Measures which are more subjective or hard to assess from the outside, like user-friendliness and public engagement, are, however, not part of the criteria. Nor is the publication of documents that fall outside the categories of the IATI standards. So, for a donor organization whose primary goal is to do well in the ranking, it is tempting to sacrifice improvement in user-friendliness, the level of public engagement and publication of documents that do not fit within the IATI framework.

Indeed, for the political leadership in Swedish international development aid, topping the ranking was a top priority made explicit by the State Secretary of development aid a few years after the launch:

\section{"I called the Director General of Sida and the chief official for development aid at the Ministry for Foreign Affairs to a crisis meeting. The ranking has come. Next time I want us to top it! I understand how it sounds, it is not an end in itself, but topping the ranking should be a side-effect of our level of ambition."}

The political ambition to top the rankings immediately trickled down to the organization that administered and continued to develop the application. The project manager for continued development after the launch was very clear about this:

"For us, it is important to end up higher in the rankings. It is, after all, the ranking that everybody looks at and it is like its own little world."

That ambition was not only explicit on the political level and communicated to Sida and project management, but it had also been made clear to the programmers in the development project. One of them commented:

“They don't care much about the publication of documents on Openaid. They are 100\% focused on IATI publications to increase their transparency rating." 
The yearly assessment and report from PWYF has become the industry's yardstick for evaluation and what counts as a qualitative transparency system among peers. PWYF has successfully set the agenda for development. It has helped to put pressure on donor organizations, which has led to a rapid development among the more ambitious donor organizations to increase transparency in terms of presenting comprehensive, comparable, accessible and timely data.

Not only does a yearly ranking put pressure on development, but it also provides a roadmap for what needs to be done-both to improve transparency and to improve rankings. In the case of Openaid, one can follow the progression in the ranking protocols over the years as features are added or quality is improved in criteria that are measured by PWYF. What remains unimproved, so far, is the citizen dialogue.

\section{5 | CONCLUSIONS: PROBLEMS, OPPORTUNITIES AND THE POSSIBILITY OF A RECONNECTION}

Empirical findings show that Openaid has not gained a foothold among the public, nor has it done so among third party intermediaries. This is not because the system fails at providing transparency (it provides lots of detailed information and data about many activities), but because it does so in a form that was perceived to be difficult to digest even by seasoned professionals in the aid industry.

The fact that Openaid has, so far, failed to become relevant to the public doesn't mean that it is withering away. Nor does it mean that there is no momentum driving its further development. Instead, other driving forces have stepped in. Aid professionals at Sida have found Openaid a practical tool to access information and documents for their own projects. Soon after the launch, internal users also became a prioritized user whose needs were to be considered for further application development. Additionally, and more importantly, the political system, fuelled by international rankings, is putting pressure on Sida to fill the gaps specified in ranking assessment protocols, so as to improve performance in future rankings. The progression from year to year in the scores of rankings shows a continuous improvement in compliance with assessment criteria.

Openaid hasn't yet become relevant to the public if the level of use by ordinary citizens is our yardstick. It was a political project from the start, with the intention of putting it in the hands of the public, thereby initiating a dynamic that would lead to processes reshaping development aid for the better in terms of transparency, resource utilisation and results. The impact on aid effectiveness that was part of the initial goals is nowhere to be seen, so far. At best, it can be said to have increased internal administrative efficiency, since it allows staff to easily retrieve project documents and data even when out in the field.

The handover from the political system to the public is yet to happen. In terms of primary users, Openaid is still in the hands of the political system. This may continue for as long as government officials find it important to do well in international rankings and worthwhile to have a "flagship" application representing Sweden's ambitions, not only in the limited field of international development aid, but also government transparency in general. As such, Openaid became a political trophy, even in the absence of the originally desired results.

We previously discussed the intended action circle (Figure 2); a simplified model of what the originators of Openaid sought to achieve. Empirical findings present us with a different picture of which the driving forces are. Instead of being embedded in a dialogue with the public, a rather different action cycle has emerged. The driving force in the present action cycle is the pressure applied by the political system as a result of the relative performance of the transparency system in international rankings, rather than the ongoing dialogue with an interested public. 


\section{Intended Openaid Action Circle}

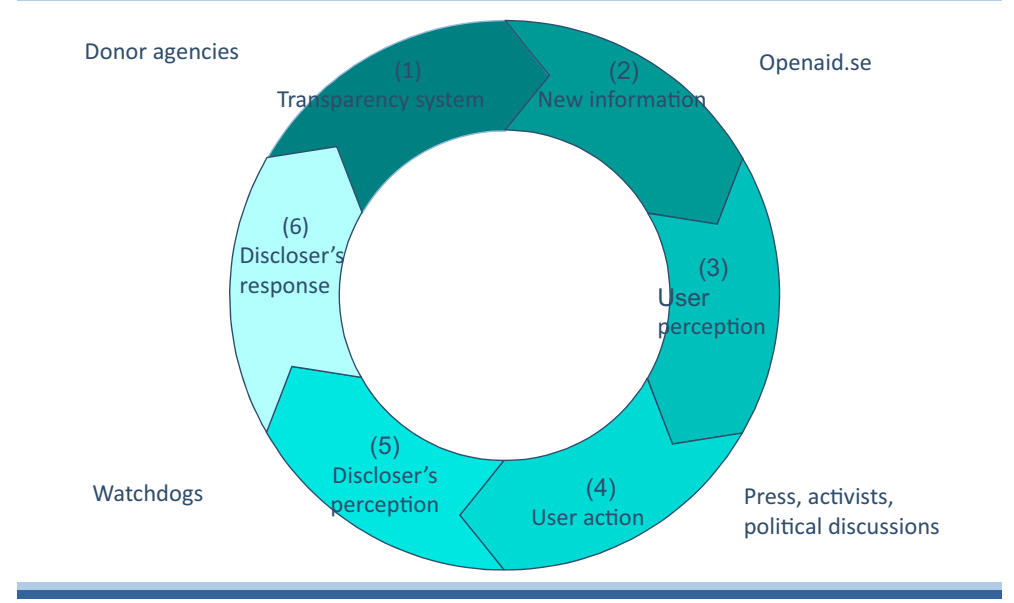

F IG URE 2 Intended Openaid action circle

A modified version which gives a better picture of how the present action circle works, based on empirical evidence, would look like the figure (Figure 3) below:

(1) The transparency system (2) compels all agencies and organizations funded by Swedish official development aid to report all disbursements, basic descriptions and sometimes also additional documents on an activity level. (3) The formal commitment to transparency and compliance with IATI standards are scrutinized by PWYF who (4) issues a rating in which all donor systems are assessed and rated. (5) Members of the political system put pressure on the principal of Openaid to take action

\section{Present Openaid Action Circle}

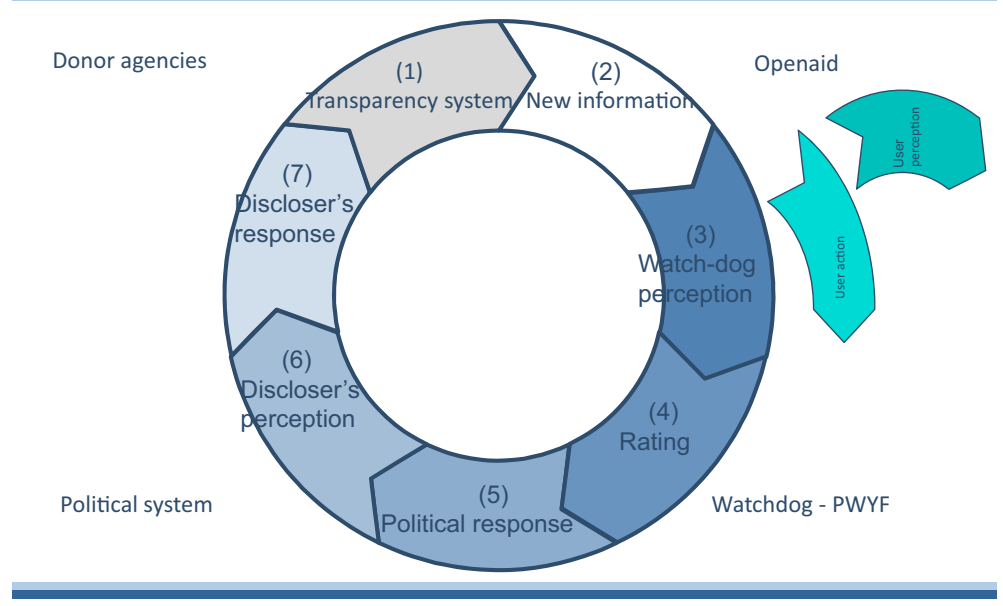

F IG URE 3 Present Openaid action circle 
to improve future rating, (6) which is duly noted and (7) the development organization can use rating protocols as actionable indicators to improve individual features with low scores, (1) after which the cycle starts anew. Noteworthy in the present action cycle above is that the citizen/taxpayer, occupying a central role in the intended action circle (Figure 2), has no important role.

The pattern described above is in several important ways not specific to Openaid. As discussed at the beginning, the citizens are conspicuous by their absence in most transparency systems (McGee, 2013). This leaves no opportunity for a user dialogue of the form discussed by Fung et al. (2004). However, at the same time, we are witnessing a steady international development and progression towards compliance with IATI data standards (PWYF, 2012; 2013; 2014). Not all major donor organizations are working hard to improve their transparency, but the general level, as measured in rankings, is on the rise. It can be questioned, however, how fruitful this development is, if there is nobody but the watchdog to be transparent to. Especially in a situation where the main focus of the watchdog is to scrutinize the formal properties of the reported information, rather than its content (Power, 1997).

As with previous research on other transparency systems for development aid, we have seen that citizen dialogue has had a minimal role in the use and further development of Openaid. Instead, contrary to earlier literature, we have identified other actors and driving forces which provide both legitimacy and political status.

The conclusion so far must be that the findings do not fit the model with citizen dialogue as driving force, but that PWYF, IATI and national as well as international political actors have stepped in to continually push Openaid towards continuous development. The questions, then, are: development for whom and what might it lead to in the future?

\section{1 | Future implications - an era of indirect use?}

So far, empirical evidence and the conclusions they lead to present us with a rather gloomy picture, not least from a practitioner's perspective. The hopes of catalytic change envisioned by the originators of Openaid are yet to be fulfilled. However, if we allow ourselves to speculate on possible future developments, there are quite plausible alternatives where new groups, which presently are practically or completely absent, enter the action circle and fundamentally reshape it.

Repeatedly, history has shown that innovation and development have flourished when different actors have been able to access an open and standardized digital ecosystem that serves as a platform for reuse and innovation (O'Reilly, 2010). Instead of the original proprietors of information and technology jealously guarding their domain, new actors are allowed, or even encouraged, to experiment and innovate by exploiting the possibilities offered by the platform.

Today, it is quite possible that we are witnessing a first stage of infrastructure building before the take-off of such a development, with standardized IATI data from multiple sources as the common platform for reuse and innovation. Such a development would make use of the data that could be combined from sources such as Openaid and other transparency systems, sharing common standards, which are brought together in the IATI repository. Data could also be collected from each individual transparency system, but the individual donors' transparency systems as such would not be used to interact with users. Rather, the interaction with users would be performed through mobile or computer apps presented by third party developers. Openaid, and other transparency systems, could potentially have large numbers of future users without necessarily having any direct user interaction or, even, without providing its own user application and interface. Thus, it is not necessarily important that Openaid is used, but much more so that its data are.

For development of apps by third party developers to begin, it is essential that data is available for free and can be downloaded in machine-readable format over the Internet (Robinson et al., 2010). 
This is already the case. Data can be downloaded from the central IATI repository, which is updated by individual donor transparency systems. It can also be retrieved directly from each donor system. Also, it is already the case that different sources of data share a common standard - IATI. Building a third party application based on data from numerous sources which all have their idiosyncratic formats would be a hopeless task. Thus, the most basic components, standardized data which can be downloaded in bulk for free over the Internet, are in place for a common infrastructure for transparency systems for international development aid.

Previously, we noted that, besides donor commitment to transparency, data compliance and comprehensiveness is essentially what is measured in the PWYF rankings. The yearly rankings, in turn, indicate that not only Openaid, but also the collective of donor transparency systems, are progressing towards increased comprehensiveness and compliance with IATI standards. Thus, it is quite possible that data on international development aid is nearing a tipping-point, where it is of sufficient quality to be brought together and fuel innovation by third party developers of apps for computers and mobiles.

What's the big deal with bringing together data from all donors? Why not focus on trying to make local donor applications more palatable to the now absent citizen? The main reason is, of course, that bringing together timely data of high quality from many donors presents us with the potential to give a broader picture of joint projects, involving many organizations, and also to combine data on recipient level. It could be brought together and combined to give a composite picture of what goes on in different fields of aid or to present what is currently happening in countries that receive development aid. This may not sound like a big deal, but could potentially be a game changer.

In practice, this could make aid transparency more interesting to the citizens in donor countries, but, above all, it could bring about a shift from transparency for taxpayers to transparency for aid recipients and for learning. When comprehensive aid data from multiple donors can be downloaded for free in a standard format, third party developers can assemble and present, on different levels, what is going on, what has been achieved, what seems to work, etc. This has the potential not only to enhance transparency and accountability, but also to improve one of the most underestimated objectives of transparency: learning.

Reaching the tipping-point where the general comprehensiveness and quality of standardized aid data sparks the innovation of third party apps could possibly present us with a future action circle of transparency systems that looks radically different from the present. Innovation for apps which can be used in devices of cheap technology has the potential to also involve both the now absent citizen as well as the recipients of development aid, thus presenting us with a future action circle resembling the figure (Figure 4) below:

(1) Transparency systems from multiple countries and organizations publish timely data following IATI standards (2) which are picked up by third party developers who present information in different, accessible and interesting ways to (3) citizens of donor and recipient countries, activists, journalists and others. (4) Users assimilate, disseminate, evaluate and act upon information in ways which creates dialogues with (5) disclosing agencies, who also (6) respond by taking action to improve the transparency system as well as operative activities, (1) after which the cycle starts anew.

The present action circle steadily improves donor commitment to transparency and IATI compliance. The future action circle presented above has the potential to engage different user groups, improve communication processes, create better transparency, but also to transcend transparency and even accountability thereby being part of the feedback and learning processes that could lead to the transformative change that Tisné (2010) hoped for. Indeed, an era of indirect use of aid data coupled with development of interesting apps for various user groups, not least citizens of recipient countries, might be instrumental in helping to bring about that catalytic change. 


\section{Future Transparency Action Circle?}

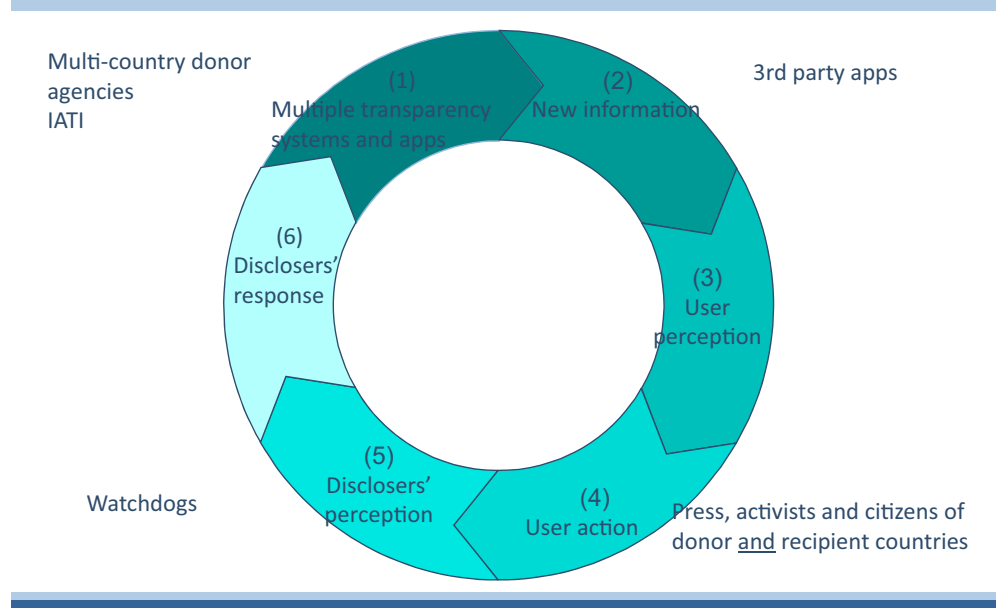

F IG URE 4 Future transparency action circle

In the model above, the future transparency action circle, we have in a sense come back to the original action circle put forth by Fung et al. (2004). Once more, different forms of users outside the political system are part of the action circle. It would even go beyond the aspirations of Openaid's originators, since not only citizens of donor countries, but also those of recipient countries would be part of the action circle.

One of the implications of previous findings and conclusions is that for the potential of the future action circle to be achieved, policy-makers must actively mobilize third party developers to get the ball rolling. It does not suffice to produce information from the transparency system. Someone must help us to pose the pertinent questions and to make the relevant comparisons. The transparency system needs to be an open transparency "space", into which third party actors are invited and encouraged to contribute. Only then can transparency systems for development aid contribute to catalytic change.

It is quite possible that the case presented in this article is idiosyncratic in many important respects. Further and broader research might reveal that the historic and present driving forces of other transparency systems are quite different. They could also be developing in quite different directions. This, however, is probably not a problem. It could even be a driver of innovation, as long as there is a common information infrastructure for transparency systems that is steadily improving.

\section{REFERENCES}

Avila, R., Feigenblatt, H., Heacock, R., \& Heller, N. (2011). Global mapping of technology for transparency and accountability: New technologies. Retrieved from the Transparency and Accountability Initiative website: http://www. transparency-initiative.org/wp-content/uploads/2017/03/global_mapping_of_technology_final1.pdf

Belal, A. R., Cooper, S. M., \& Roberts, R. W. (2013). Vulnerable and exploitable: The need for organisational accountability and transparency in emerging and less developed economies. Accounting Forum, 37, 81-91. https://doi. org/10.1016/j.accfor.2013.04.001

Bertot, J. C., Jaeger, P. T., \& Grimes, J. M. (2010). Using ICTs to create a culture of transparency: E-government and social media as openness and anti-corruption tools for societies. Government Information Quarterly, 27, $264-271$. https://doi.org/10.1016/j.giq.2010.03.001 
Brown, H. S., de Jong, M., \& Lessidrenska, T. (2009). The rise of the Global Reporting Initiative: A case of institutional entrepreneurship. Environmental Politics, 18, 182-200. https://doi.org/10.1080/09644010802682551

Carter, B. (2014). Transparency and accountability (GSDRC Helpdesk Research Report No. 1067). Retrieved from: https://www.gov.uk/dfid-research-outputs/transparency-and-accountability-gsdrc-helpdesk-research-report-1067

Florini, A. M. (2000). Does the invisible hand need a transparent glove? The politics of transparency. Proceedings of the 11th Annual World Bank Conference on Development Economics. Retrieved from the World Bank website: http:// siteresources.worldbank.org/INTWBIGOVANTCOR/Resources/florini.pdf

Fox, J. (2007). The uncertain relationship between transparency and accountability. Development in Practice. 17, 663671. https://doi.org/10.1080/09614520701469955

Fung,A.,Graham,M.,\&Weil,D.(2003).Thepoliticaleconomyoftransparency: Whatmakesdisclosurepoliciessustainable? (KSGFaculty Research Working Papers Series RWP03-039). Retrieved from Harvard Kennedy School website: https:// www.hks.harvard.edu/publications/political-economy-transparency-what-makes-disclosure-policies-sustainable-0\#

Fung, A., Weil, D., Graham, M., \& Fagotto, E. (2004). The political economy of transparency: What makes disclosure policies effective? Retrieved from Ash Institute for Democratic Governance and Innovation, Harvard University, website: https://ash.harvard.edu/files/political_econ_transparency.pdf

Gallhofer, S., Haslam, J., \& van der Walt, S. (2011). Accountability and transparency in relation to human rights: A critical perspective reflecting upon accounting, corporate responsibility and ways forward in the context of globalisation. Critical Perspectives on Accounting, 22, 765-780. https://doi.org/10.1016/j.cpa.2011.07.002

Gaventa, J., \& McGee, R. (2013). The impact of transparency and accountability initiatives. Development Policy Review, 31(s1), s3-s28. https://doi.org/10.1111/dpr.12017

Hale, T. (2008). Transparency, accountability and global governance. Global Governance, 14, 73-94.

Hess, D. (2007). Social reporting and new governance regulation: The prospects of achieving corporate accountability through transparency. Business Ethics Quarterly, 17, 453-476. https://doi.org/10.5840/beq200717348

Janssen, M., Charalabidis, Y., \& Zuiderwijk, A. (2012). Benefits, adoption barriers and myths of open data and open government. Information Systems Management, 29, 258-268. https://doi.org/10.1080/10580530.2012.716740

Joshi, A. (2013). Do they work? Assessing the impact of transparency and accountability initiatives in service delivery. Development Policy Review, 31(s1), s29-s48. https://doi.org/10.1111/dpr.12018

Kalampokis, E., Tambouris, E., \& Tarabanis, K. (2011). A classification scheme for open government data: Towards linking decentralised data. International Journal of Web Engineering Technology, 6, 266-285. https://doi. org/10.1504/IJWET.2011.040725

Kuriyan, R., Bailur, S., Gigler, B., \& Park, K. (2012). Technologies for transparency and accountability. Washington D.C.: World Bank.

Linders, D. (2012). From e-government to we-government: Defining a typology for citizen coproduction in the age of social media. Government Information Quarterly, 29, 446-454. https://doi.org/10.1016/j.giq.2012.06.003

Linders, D. (2013). Towards open development: Leveraging open data to improve the planning and coordination of international aid. Government Information Quarterly, 30, 426-434. https://doi.org/10.1016/j.giq.2013.04.001

McGee, R. (2013). Aid transparency and accountability: "Build it and they'll come"? Development Policy Review, 31(s1), s107-s124. https://doi.org/10.1111/dpr.12022

Mejía Acosta, A. (2013). The impact and effectiveness of accountability and transparency initiatives: The governance of natural resources. Development Policy Review, 31(s1), s89-s105. https://doi.org/10.1111/dpr.12021

O'Reilly, T. (2010). Government as a platform. In D. Lathrop \& L. Ruma (Eds.), Open Government (pp. 11-39). Sebastopol, CA: O’Reilly Media.

Power, M. (1997). The Audit Society: Rituals of Verification. Oxford: Oxford University Press.

Publish What You Fund. (2012). Aid Transparency Index. Retrieved from: http://www.publishwhatyoufund.org/ wp-content/uploads/2016/12/2012-Aid-Transparency-Index.pdf

Publish What You Fund. (2013). Aid Transparency Index. Retrieved from: http://www.publishwhatyoufund.org/ wp-content/uploads/2016/12/2013-Aid-Transparency-Index.pdf

Publish What You Fund. (2014). Aid Transparency Index. Retrieved from: http://www.publishwhatyoufund.org/ wp-content/uploads/2016/12/2014-Aid-Transparency-Index.pdf

Publish What You Fund. (2016). Aid Transparency Index. Retrieved from: http://www.publishwhatyoufund.org/ wp-content/uploads/2016/12/2015-EU-Aid-Transparency-Review.pdf

Robinson, D. G., Yu, H., \& Felten, E. (2010). Enabling innovation for civic engagement. In D. Lathrop \& L. Ruma (Eds.), Open Government (pp. 83-90). Sebastopol, CA: O’Reilly Media. 
Strathern, M. (2000). The tyranny of transparency. British Educational Research Journal, 26, 309-321. https://doi. org/10.1080/713651562

Tisné, M. (2010). Harnessing the potential of new technologies in government reform (Note for World Bank). Retrieved from the World Bank website: http://siteresources.worldbank.org/INFORMATIONANDCOMMUNICATIONA NDTECHNOLOGIES/Resources/TAI_Note_by_MartinTisneforpresentation.pdf

Weil, D., Fung, A., Graham, M., \& Fagotto, E. (2006). The effectiveness of regulatory disclosure policies. Journal of Policy Analysis and Management, 25, 155-181. https://doi.org/10.1002/pam.20160

How to cite this article: Hedlin P. And yet they thrive!-Regaining the relevance of a transparency system. Dev Policy Rev. 2017;00:1-19. https://doi.org/10.1111/dpr.12358 